\title{
Adsorption Properties and Inhibition of Carbon Steel Corrosion in a Hydrochloric Solution by 2-(4,5-diphenyl-4,5-dihydro-1h-imidazol-2-yl)-5-methoxyphenol
}

\author{
M. Rbaa, ${ }^{a}$ M. Galai, ${ }^{b}$ Y. El Kacimi, ${ }^{b,}$ M. Ouakki, ${ }^{c}$ R. Touir, ${ }^{a}$ \\ B. Lakhrissi ${ }^{a}$ and M. Ebn Touhami ${ }^{b}$ \\ ${ }^{a}$ Laboratory of Agricultural Resource Polymers and Engineering, Faculty of Science, \\ Ibn Tofail University, P.O. Box 133-14000, Kenitra, Morocco \\ ${ }^{b}$ Laboratory of Materials Engineering and Environment: Modeling and Application, \\ Faculty of Science, Ibn Tofail University, P.O. Box 133-14000, Kenitra, Morocco \\ ${ }^{c}$ Laboratory of Materials, Electrochemistry and Environment, Faculty of Science, \\ Ibn Tofail University, Kenitra, Morocco
}

Received November 08, 2016; accepted April 28, 2017

\begin{abstract}
The corrosion inhibition of mild steel in a 1.0 M hydrochloric acid solution by 2-(4,5diphenyl-4,5-dihydro-1h-imidazol-2-yl)-5-methoxyphenol (P1) has been studied in relation to the concentration of the inhibitor, as well as to the temperature, using chemical (weight loss) and electrochemical techniques. All the employed methods were in reasonable agreement. The protection efficiency increased with an increased inhibitor's concentration. The obtained thermodynamic adsorption parameters $\left(\Delta \mathrm{G}^{*}\right.$ ads, $\Delta \mathrm{H}^{*}$ ads, $\Delta \mathrm{S}^{*}$ ads) indicated that this polymer retarded both cathodic and anodic processes through physical adsorption, and blocked the active corrosion sites. It was also found that this compound obeyed the Langmuir's adsorption isotherm.
\end{abstract}

Keywords: Corrosion and inhibition; imidazole; carbon steel, hydrochloric acid; adsorption isotherm; thermodynamic parameters.

\section{Introduction}

Carbon steel is among the most widely used engineering materials in various areas such as metal-processing equipment, marine applications, nuclear and fossil fuel power plants, transportation, chemical processing, pipelines, mining and construction. Iron and its alloys, as construction materials in industrial sectors, have become a great challenge for corrosion engineers or scientists nowadays [1]. Acid solutions are commonly used for the removal of undesirable scale and rust in metalworking, boilers cleaning and heat exchangers. However, overpickling of metal leads to a rough and blistered coating. The formation of a

\footnotetext{
* Corresponding author. E-mail address: elkacimiyounes@yahoo.fr
} 
protective film on the steel surface, and the characterization of this metal surface is the major subject of interest of this study. In order to reduce the corrosion rate of metals, several techniques have been applied. The use of inhibitors is one of the most practical methods for protection against corrosion in acidic media. Inhibitors, which reduce corrosion on metallic materials, can be divided into three kinds: surfactant inhibitors [2], organic inhibitors [3] and inorganic inhibitors [4]. Heterocyclic inhibitors have many advantages, such as high inhibition efficiency [5-8], low price, and easy production. The choice of effective inhibitors was based on their mechanism of action and their electrondonating capability. Moreover, organic molecules can be adsorbed on the metal surface by one of the four following mechanisms: (i) electrostatic interaction between the charged surface of the metal and the charge of the inhibitor; (ii) interaction of unshared electron pairs in the inhibitor molecule with the metal; (iii) interaction of $\pi$-electrons with the metal; and (iv) a combination of the (i) and (iii) types [9-11].

In the others, these compounds can form either a strong coordination bond with the metal atom or a passive film on the surface [12]. The corrosion inhibition of a metal may involve either physisorption or chemisorption of the inhibitor on the metal surface. Electrostatic attraction between the charged hydrophilic group and the charged active centers on the metal surface leads to physisorption. Several authors showed that most inhibitors were adsorbed on the metal surface by displacing water molecules from the surface and forming a compact barrier film [13].

The aim of this work is to evaluate the corrosion inhibition efficiency of 2-(4,5diphenyl-4,5-dihydro-1h-imidazol-2-yl)-5-methoxyphenol (P1) for carbon steel in a $1.0 \mathrm{M} \mathrm{HCl}$ solution using weight loss measurements, potentiodynamic polarization and electrochemical impedance spectroscopy. The effect of temperature on the corrosion behavior was also studied in the range from $298 \pm 2$ to $328 \pm 2 \mathrm{~K}$. The adsorption thermodynamic parameters, such as adsorption heat, $\Delta \mathrm{H}_{\mathrm{a}}{ }^{*}$, entropy of adsorption, $\Delta \mathrm{S}_{\mathrm{a}}{ }^{*}$, and adsorption of free energy, $\Delta \mathrm{G}_{\mathrm{a}}$, were calculated and discussed.

\section{Experimental details}

\section{Weight loss measurements}

The chemical composition of the used carbon steel sample is shown in Table 1. The specimen's surface was prepared by polishing it with emery paper at different grit sizes (from 180 to 1200), rinsing with distilled water, degreasing with ethanol, and drying it at hot air.

Table 1. Chemical composition of the used carbon steel.

\begin{tabular}{|c|c|c|c|c|c|c|c|c|c|c|c|c|}
\hline \multirow[t]{2}{*}{ Material } & \multicolumn{12}{|c|}{ Composition, $\%$ by wt. } \\
\hline & $\mathbf{C}$ & Si & Mn & $\mathrm{Cr}$ & Mo & $\mathrm{Ni}$ & Al & $\mathbf{C u}$ & Co & $\mathbf{V}$ & $\mathbf{W}$ & $\mathbf{F e}$ \\
\hline Carbon steel & 0.11 & 0.24 & 0.47 & 0.12 & 0.02 & 0.1 & 0.03 & 0.14 & $<0.0012$ & $<0.003$ & 0.06 & Balance \\
\hline
\end{tabular}


The used carbon steel specimens have a rectangular form with $2.5 \mathrm{~cm} \times 2.0 \mathrm{~cm} \times$ $0.05 \mathrm{~cm}$. The immersion time for weight loss was $6 \mathrm{~h}$ at $298 \pm 2 \mathrm{~K}$. After the immersion period, the specimens were cleaned according to ASTM G-81, and reweighed to $10^{-4} \mathrm{~g}$ to determine the corrosion rate $[14,15]$. The aggressive solution of $1.0 \mathrm{M} \mathrm{HCl}$ was prepared by dilution of $37 \% \mathrm{HCl}$ analytical grade with distilled water. The molecular formula of the examined inhibitor is shown in Fig. 1.

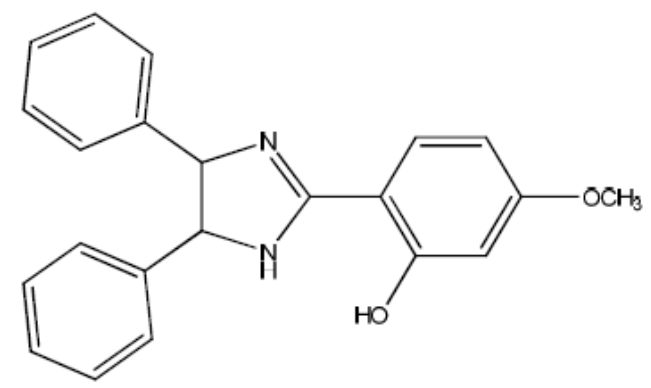

Figure 1. Chemical structure of 2-(4,5-diphenyl-4,5-dihydro-1h-imidazol-2-yl)-5methoxyphenol.

However, weight loss allows us to calculate the mean corrosion rate, as expressed in $\mathrm{mg} \mathrm{cm}^{-2} \mathrm{~h}^{-1}$.

The inhibition efficiency, $\eta_{\mathrm{w}} \%$, is determined as follows:

$$
\eta_{\omega} \%=\frac{\omega_{c o r r}^{0}-\omega_{c o r r}}{\omega_{c o r r}^{0}} \times 100
$$

where $\omega^{0}$ corr and $\omega_{\text {corr }}$ are the corrosion rates in the absence and presence of inhibitors, respectively.

\section{Electrochemical measurements}

For electrochemical measurements, the electrolysis cell was a borosilicate glass $\left(\right.$ Pyrex $\left.^{\circledR}\right)$ cylinder closed by a cap with five apertures. Three of them were used for the electrode insertions. The working electrode was pressure-fitted into a polytetrafluoroethylene holder (PTFE), only exposing $1 \mathrm{~cm}^{2}$ of area to the solution. Platinum and saturated calomel were used as counter and reference electrodes (SCE), respectively. All potentials were measured against the last electrode.

The potentiodynamic polarization curves were recorded by automatically changing the electrode potential from negative values to positive values versus $E_{\text {corr }}$, using a Potentiostat/Galvanostat type PGZ 100, at a scan rate of $1.0 \mathrm{mV} \mathrm{s}^{-1}$, after 30 min immersion time until reaching a steady state. The test solution was thermostatically controlled at $298 \pm 2 \mathrm{~K}$ in air atmosphere without bubbling. To evaluate corrosion kinetic parameters, a fitting by Stern-Geary equation was used. To do so, the overall current density values, $i$, were considered as the sum of two contributions, anodic and cathodic current, $i_{a}$ and $i_{c}$, respectively. For the potential domain, not too far from the open circuit potential, it may be considered 
that both processes followed the Tafel law [16]. Thus, it can be derived from equation (2):

$$
i=i_{\mathrm{a}}+i_{\mathrm{c}}=i_{\text {corr }}\left\{\exp \left[b_{\mathrm{a}} \times\left(E-E_{\text {corr }}\right)\right]-\exp \left[b_{\mathrm{c}} \times\left(E-E_{\text {corr }}\right)\right]\right\}
$$

where $i_{\text {corr }}$ is the corrosion current density $\left(\mathrm{A} \mathrm{cm}^{-2}\right)$, and $b_{a}$ and $b_{c}$ are the Tafel constants of anodic and cathodic reactions $\left(\mathrm{V}^{-1}\right)$, respectively. These constants are linked to the Tafel slopes $\beta$ (V/dec) in a usual logarithmic scale given by equation (3):

$$
\beta=\frac{\ln 10}{b}=\frac{2.303}{b}
$$

The corrosion parameters were then evaluated by means of the nonlinear least square method, applying equation (2), using Origin software. However, for this calculation, the applied potential range was limited to $\pm 0.100 \mathrm{~V}$ around $\mathrm{E}_{\mathrm{corr}}$, and a significant systematic divergence was sometimes observed for both anodic and cathodic branches.

The corrosion inhibition efficiency is evaluated from the corrosion current densities values using the relationship (4):

$$
\eta_{\mathrm{PP}}=\frac{i_{\text {corr }}^{0}-i_{\text {corr }}}{i_{\text {corr }}^{0}} \times 100
$$

The surface coverage values, $(\theta)$, have been obtained from polarization curves for various concentrations of inhibitor using the following equation [17]:

$$
\theta=1-\frac{i_{\text {corr }}}{i_{\text {corr }}^{0}}
$$

where $i_{\text {corr }}^{0}$ and $i_{\text {corr }}$ are the corrosion current densities values without and with inhibitor, respectively.

The electrochemical impedance spectroscopy measurements were carried out using a transfer function analyzer (VoltaLab PGZ 100), with a small amplitude, a.c., signal $(10 \mathrm{mV} \mathrm{rms})$, over a frequency domain from $100 \mathrm{kHz}$ to $100 \mathrm{mHz}$, with five points per decade. The EIS diagrams were done in the Nyquist representation. The results were then analyzed in terms of an equivalent electrical circuit using Bouckamp program [18].

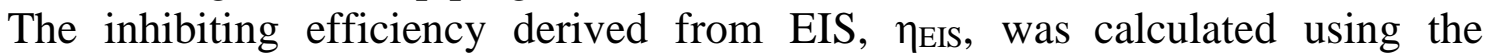
following equation (6):

$$
\eta_{\mathrm{EIS}}=\frac{R_{\mathrm{ct}}-R_{\mathrm{ct}}^{0}}{R_{\mathrm{ct}}} \times 100
$$

where $R_{\mathrm{ct}}^{0}$ and $R_{\mathrm{ct}}$ are the charge transfer resistance values in the absence and in the presence of inhibitor, respectively.

In order to ensure reproducibility, all experiments were three times repeated. The evaluated inaccuracy did not exceed $10 \%$. 


\section{Results and discussion}

\section{Weight loss measurements}

The corrosion rate of carbon steel in $1.0 \mathrm{M} \mathrm{HCl}$, with and without different concentrations of P1, was determined after $6 \mathrm{~h}$ of immersion at $298 \pm 2 \mathrm{~K}$. This choice of immersion time was based on literature [19]. The obtained results are presented in Table 2. It has been observed that the inhibition efficiency increased with the concentration of $\mathrm{P} 1$, reaching a maximum at $10^{-3} \mathrm{M}$ of $\mathrm{P} 1$. This behavior could be attributed to the increase in adsorption of the inhibitor at the metal/solution interface when its concentration is increased. So, an increase of inhibitor's concentration beyond $10^{-3} \mathrm{M}$ resulted on a decrease in corrosion protection. The participation of the phenyl ring, in addition to that of the $\mathrm{N}$ atom during the adsorption process, may be confirmed by changing the $\pi$-electron density on the phenyl ring, substituting the electron donating $\left(-\mathrm{OH}\right.$ and $\left.-\mathrm{O}-\mathrm{CH}_{3}\right)$ group. Generally, the electron donating groups increase the inhibition efficiency of the inhibitors.

Table 2. Corrosion rate and inhibition efficiency of carbon steel in $1.0 \mathrm{M} \mathrm{HCl}$, with different concentrations of P1 at $298 \pm 2 \mathrm{~K}$ after $6 \mathrm{~h}$ of immersion.

\begin{tabular}{lccc}
\hline Inhibitor & Conc. $(\mathbf{p p m})$ & $\omega_{\text {corr }}\left(\mathbf{m g ~ c m} \mathbf{c m}^{-\mathbf{2}} \mathbf{h}^{-\mathbf{1}}\right)$ & $\boldsymbol{\eta}_{\boldsymbol{\omega}}(\%)$ \\
\hline Blank solution & 00 & 42.12 & - \\
\hline & $10^{-6}$ & 6.60 & 84.3 \\
& $10^{-5}$ & 5.52 & 86.9 \\
& $10^{-4}$ & 4.90 & 88.4 \\
& $10^{-3}$ & 3.15 & 92.5
\end{tabular}

\section{Potentiodynamic polarization curves}

Potentiodynamic polarization curves of carbon steel in $1.0 \mathrm{M} \mathrm{HCl}$, without and with different concentrations of $\mathrm{P} 1$ at 298 2 K, are given in Fig. 2, and their extrapolation parameters and inhibition efficiencies are plotted in Table 3. It can be seen that the P1 addition hindered the acid attack on carbon steel, and an increase in its concentration gave a decrease in anodic and cathodic current densities, indicating that this inhibitor acted as a mixed-type inhibitor. However, the inhibitor addition does not change the hydrogen evolution reaction mechanism, such as indicated by the slight changes in the cathodic slopes $\left(\beta_{\mathrm{c}}\right)$ values. This indicated that the hydrogen evolution is activation controlled [20, 21]. It is also seen that the inhibition efficiency increased with the concentration, reaching a maximum of $92.9 \%$ at $10^{-3} \mathrm{M}$ of $\mathrm{P} 1$, and exhibited both cathodic and anodic inhibition through adsorption on the carbon steel surface, blocking active sites [21]. So, a slight definite change on the corrosion potential ( $\left.E_{\text {corr }}\right)$ was observed. According to Riggs [22] and other authors, if the displacement in E (i) is $>85 \mathrm{mV} / \mathrm{E}_{\text {corr }}$, the inhibitor can be seen as of the cathodic or anodic type; (ii) if the displacement in $\mathrm{E}$ is $<85 \mathrm{mV} / \mathrm{E}_{\text {corr }}$, the inhibitor can be seen as of the mixed type. In our study, the maximum displacement is less than $85 \mathrm{mV} / \mathrm{E}_{\text {corr, }}$, which indicates that P1 is a mixed type inhibitor. The results obtained by potentiodynamic polarization curves confirmed those obtained by weight loss measurements. 


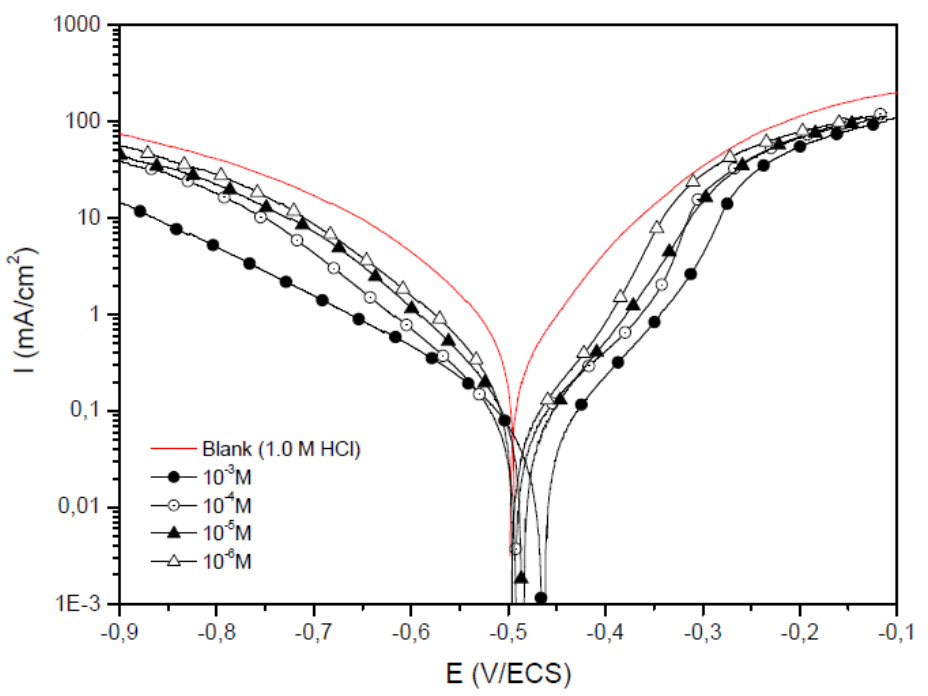

Figure 2. Potentiodynamic polarization curves for carbon steel in $1.0 \mathrm{M} \mathrm{HCl}$ without and with different concentrations of $\mathrm{P} 1$.

Table 3. Electrochemical parameters for carbon steel in $1.0 \mathrm{M} \mathrm{HCl}$ at various concentrations of $\mathrm{P} 1$ at $298 \pm 2 \mathrm{~K}$.

\begin{tabular}{cccccccc}
\hline & Concentration & $\mathbf{E}_{\text {corr }}$ & $\mathbf{i}_{\text {corr }}$ & $\boldsymbol{\beta}_{\mathbf{a}}$ & $\boldsymbol{\beta}_{\mathbf{c}}$ & $\boldsymbol{\eta}_{\mathbf{P P}}$ & $\boldsymbol{\theta}$ \\
\hline Blank solution & 00 & -498 & 983 & -92 & -104 & - & - \\
\hline P1 & $10^{-6}$ & -492 & 160 & -96 & -87 & 83.7 & 0.837 \\
& $10^{-5}$ & -479 & 137 & -100 & -82 & 86.0 & 0.860 \\
& $10^{-4}$ & -482 & 100 & -106 & -80 & 89.8 & 0.898 \\
& $10^{-3}$ & -458 & 70 & -116 & -79 & 92.9 & 0.929 \\
\hline
\end{tabular}

Note: Concentration in $\mathrm{M}, \mathrm{E}_{\text {corr }}$ in $\mathrm{mV}$ (vs. SCE), $\mathrm{i}_{\text {corr }}$ in $\mu \mathrm{A} / \mathrm{cm}^{2}, \beta_{\mathrm{a}}$ and $\beta_{\mathrm{c}}$ are, respectively, of the slope of anode and cathode polarization curve, in $\mathrm{mV} \mathrm{dec}$.

\section{Electrochemical Impedance Spectroscopy (EIS)}

The aim of this part was to confirm the obtained results by potentiodynamic polarization curves and weight loss measurements. Fig. 3 presents the Nyquist plots of carbon steel in $1.0 \mathrm{M} \mathrm{HCl}$, without and with different concentrations of P1 at the corrosion potential. It can be seen that these plots were composed of one capacitive loop in the absence and presence of different concentrations of P1. This behavior can be attributed to the charge transfer of the corrosion process. It is also noted that the diameter of the semicircle increased with the inhibitor's concentration, indicating an increase in the corrosion resistance of the material [23]. However, it allowed employing a CPE element, in order to investigate the inhibitive film properties on the metallic surface. Thus, the impedance of the CPE can be described by the following equation:

$$
Z_{\mathrm{CPE}}=\left[Q(j \omega)^{n}\right]^{-1}
$$

where $\mathrm{j}$ is an imaginary number, $\mathrm{Q}$ is the frequency independent real constant, $\omega$ $=2 \pi \mathrm{f}$ is the angular frequency $\left(\mathrm{rad} \mathrm{s}^{-1}\right), \mathrm{f}$ is the frequency of the applied signal, $\mathrm{n}$ is the CPE exponent for whole number of $\mathrm{n}=1,0,-1$, and CPE is reduced to the classical lump element-capacitor $(C)$, resistance (R) and inductance (L) [24]. The use of these parameters, similar to the constant phase element (CPE), allowed the depressed feature of Nyquist plot to be readily reproduced. 
In addition, the effective calculated double layer capacitance (C) was derived from the $\mathrm{CPE}$ parameters, according to the following equation [25]:

$$
C=Q^{\frac{1}{n}} \times R^{\frac{(1-n)}{n}}
$$

The most important data obtained from the equivalent circuit are presented in Table 4 . It may be remarked that $R_{\mathrm{ct}}$ values increased while $C_{\mathrm{dl}}$ values decreased with inhibitor's concentrations, indicating that more inhibitor molecules are adsorbed on the metallic surface, and provide better surface coverage and/or enhance the thickness of the protective layer at the metal/solution interface [26, 27]. In addition, these changes in $R_{c t}$ and $C_{d l}$ can be attributed to the gradual displacement of water molecules and/or chloride ions on the carbon steel surface [28], leading to a protective solid film, and then to a decrease in the extent of dissolution reaction $[29,30]$. On its turn, the decrease of $\mathrm{C}_{\mathrm{dl}}$ with concentrations can be explained by a decrease in the local dielectric constant and/or an increase in the protective layer thickness on the electrode surface. This trend is in accordance with Helmholtz model, given by the following equation [31]:

$$
C_{d l}=\frac{\varepsilon_{0} \times \mathcal{E}}{e} \times S
$$

where $\varepsilon$ is the dielectric constant of the protective layer, $\varepsilon_{0}$ is the permittivity of free space $\left(8.854 \times 10^{-14} \mathrm{~F} \mathrm{~cm}^{-1}\right)$ and $\mathrm{S}$ is the effective surface area of the electrode.

However, the inhibition efficiencies obtained from electrochemical impedance measurements increase with concentration, and show the same trend as those obtained from potentiodynamic polarization and gravimetric measurements.
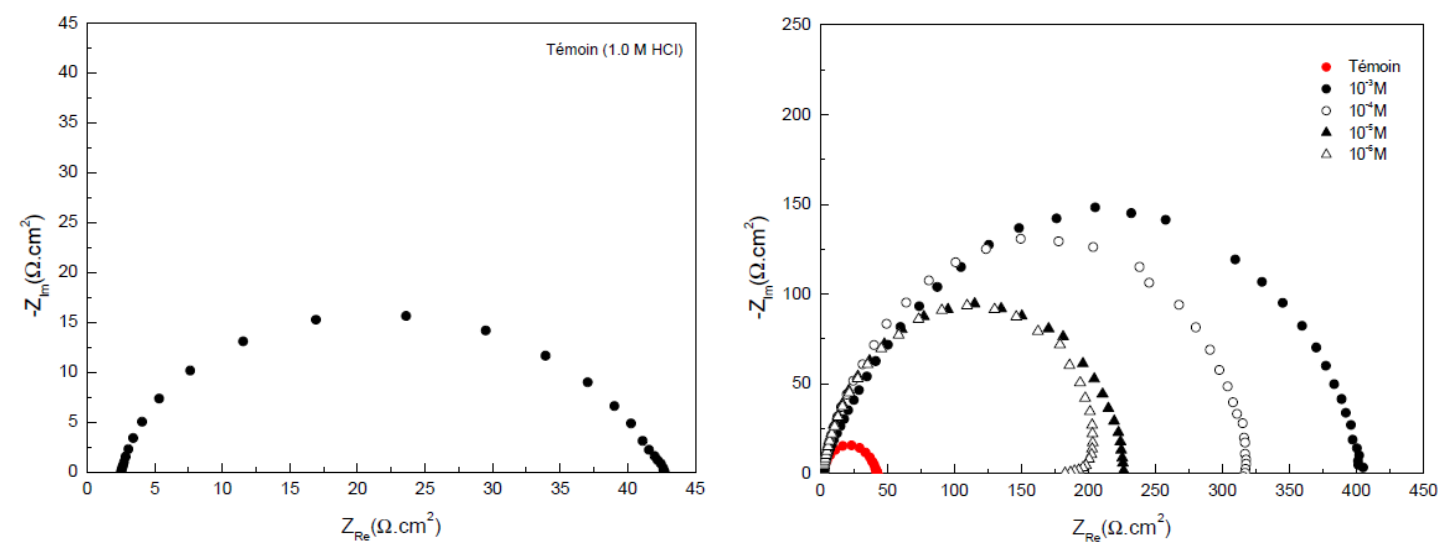

Figure 3. Nyquist plots for carbon steel in $1.0 \mathrm{M} \mathrm{HCl}$ solution in the absence and presence of various concentrations of $\mathrm{P} 1$ at $\mathrm{E}_{\text {corr }}(\mathrm{T}=298 \pm 2 \mathrm{~K})$.

However, the results can be interpreted using the equivalent circuit presented in Fig. 4, which was previously used to model the iron/acid interface [32]. Various parameters such as charge-transfer resistance $\left(R_{c t}\right)$, double layer capacitance $\left(C_{d l}\right)$ and degree of heterogeneity $\left(\mathrm{n}_{\mathrm{dl}}\right)$ obtained from impedance measurements are shown in Table 4. 
Table 4. Electrochemical impedance parameters and inhibition efficiency for carbon steel in a $1.0 \mathrm{M} \mathrm{HCl}$ solution without and with different concentrations of P1 at $298 \pm 2$ $\mathrm{K}$.

\begin{tabular}{cccc}
\hline Conc. of P1 $(\mathbf{M})$ & $\mathbf{R}_{\mathbf{c t}}\left(\boldsymbol{\Omega} \mathbf{~ c m}^{\mathbf{2}}\right)$ & $\mathbf{C}_{\mathbf{d l}}\left(\boldsymbol{\mu} \mathbf{F ~} \mathbf{~ c m}^{-2}\right)$ & $\boldsymbol{\eta}_{\text {EIS }}(\boldsymbol{\%})$ \\
\hline 00 & 35 & 298 & - \\
$10^{-6}$ & 205 & 70 & 82.9 \\
$10^{-5}$ & 235 & 62 & 85.0 \\
$10^{-4}$ & 318 & 55 & 89.0 \\
$10^{-3}$ & 404 & 50 & 91.3 \\
\hline
\end{tabular}

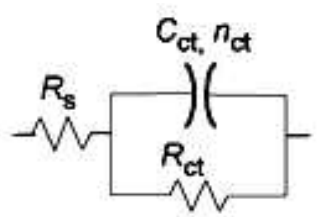

Figure 4. Equivalent circuit used to model impedance data in a $1.0 \mathrm{M} \mathrm{HCl}$ solution in the presence of different concentrations of P1.

It is obvious from the results that P1 inhibited the carbon steel corrosion in a 1.0 $\mathrm{M} \mathrm{HCl}$ solution at its different concentrations, and $\eta_{\text {EIS }}(\%)$ was seen to continuously increase with the arise in concentration, reaching a maximum of $91.3 \%$ at $10^{-3} \mathrm{M}$. The inhibition efficiencies, calculated from Tafel impedance results, showed the same trend as those obtained from EIS, polarization and weight loss measurements (Table 5).

Table 5. Inhibition efficiency values obtained from weight loss, Tafel polarization and AC impedance measurements of carbon steel in $1.0 \mathrm{M} \mathrm{HCl}$, at different concentrations of $\mathrm{P} 1$ at $298 \pm 2 \mathrm{~K}$.

\begin{tabular}{cccc}
\hline P1 Concentration & \multicolumn{3}{c}{ Inhibition efficiency $\boldsymbol{\eta}(\%)$} \\
\cline { 2 - 4 }$(\mathbf{M})$ & Weight loss & Tafel polarization & AC impedance \\
\hline $10^{-6}$ & 84.3 & 83.7 & 82.9 \\
$10^{-5}$ & 86.9 & 86.0 & 85.0 \\
$10^{-4}$ & 88.4 & 89.8 & 89.0 \\
$10^{-3}$ & 92.5 & 92.9 & 91.3 \\
\hline
\end{tabular}

\section{Effect of temperature}

Temperature can modify the interaction between the carbon steel electrode and the acidic media without and with $\mathrm{P} 1$. Thus, the potentiodynamic polarization curves for carbon steel in $1.0 \mathrm{M} \mathrm{HCl}$, in the absence and presence of $10^{-3} \mathrm{M}$ of $\mathrm{P} 1$, in the temperature range of $298 \pm 2$ to $328 \pm 2 \mathrm{~K}$, are shown in Figs. 5 and 6 , respectively. It is remarked that these curves exhibited the Tafel regions. It is also noted that the anodic and cathodic branches increased with an increase in temperature.

The various electrochemical parameters were calculated from Tafel plots, and summarized in Table 6.

It can be seen that the $i_{\text {corr }}$ increased with an increased temperature, both in uninhibited and inhibited solutions, and the values of the inhibition efficiency of P1 decreased with higher temperatures. Thus, the inhibition efficiencies of P1 are temperature-dependent. 


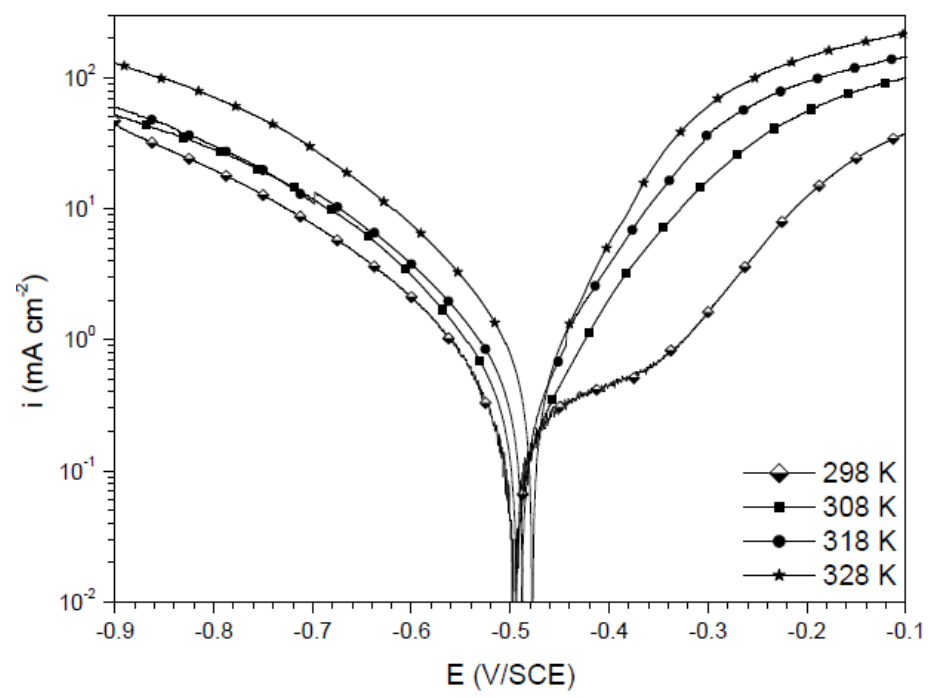

Figure 5. Potentiodynamic polarization curves for carbon steel in $1.0 \mathrm{M} \mathrm{HCl}$, in the absence of P1 at different temperatures.

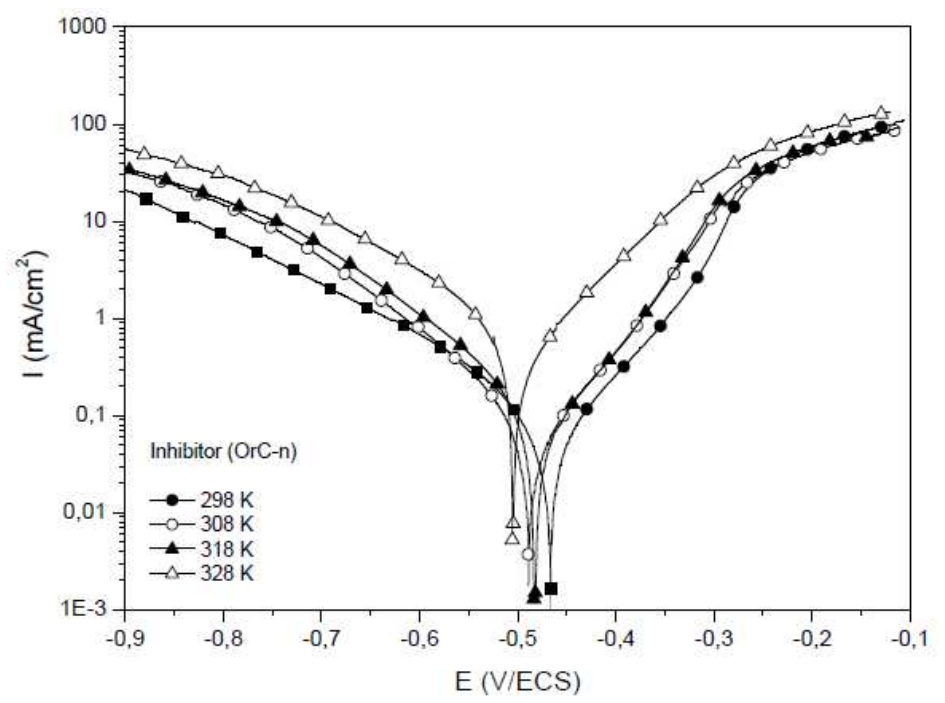

Figure 6. Potentiodynamic polarization curves for carbon steel in $1.0 \mathrm{M} \mathrm{HCl}$, in the presence of $10^{-3} \mathrm{M}$ of $\mathrm{P} 1$ at different temperatures.

Table 6. Electrochemical parameters of carbon steel in $1.0 \mathrm{M} \mathrm{HCl}$, without and with $10^{-3} \mathrm{M}$ P1 at different temperatures.

\begin{tabular}{lccccc} 
& Temp $(K)$ & $E_{\text {corr }}$ & $i_{\text {corr }}$ & $\beta_{c}$ & $\eta_{p p}$ \\
\hline Blank solution & $298 \pm 2$ & -498 & 983 & -92 & - \\
& $308 \pm 2$ & -491 & 1600 & -178 & - \\
& $318 \pm 2$ & -475 & 2420 & -165 & - \\
\hline $10^{-3}$ M of P1 & $328 \pm 2$ & -465 & 3100 & -151 & - \\
\hline $398 \pm 2$ & -458 & 70 & -116 & 92.9 \\
& $308 \pm 2$ & -480 & 100 & -103 & 91.7 \\
& $318 \pm 2$ & -477 & 140 & -100 & 90.3 \\
\hline
\end{tabular}

Note: Temperatures in $\mathrm{K}, \mathrm{E}_{\text {corr }}$ in $\mathrm{mV}$ (vs. SCE), $\mathrm{i}_{\text {corr }}$ in $\mu \mathrm{A} / \mathrm{cm}^{2}, \beta_{\mathrm{a}}$ and $\beta_{\mathrm{c}}$ are, respectively, the slope of anode and cathode polarization curves, in $\mathrm{mV} \mathrm{dec}$. 


\section{Adsorption isotherm and thermodynamic parameters}

The adsorptive behavior of a corrosion inhibitor is an important part of its study. The adsorption of inhibitors is governed by the residual charge on the metal surface, and by the inhibitor's nature and chemical structure. Two main types of adsorption of an organic inhibitor on a metal surface are physical or electrostatic adsorption and chemisorption. Chemisorption involves the share or transfer of charge from the molecules to the surface, to form a coordinate type bound. Electron transfer is typical of transition metals that have vacant low-energy electron orbital. As for inhibitors, electron transfer can be expected with compounds that have relatively loosely bound electrons. The most frequently used isotherms are Langmuir isotherm, Freundlich isotherm and Temkin isotherm $[33,34]$. All these isotherms are of the general form:

$$
f(\theta, x) \times e^{-2 \alpha \theta}=K_{a d x} \times C_{i n h}
$$

where $\mathrm{f}(\theta, \mathrm{x})$ is the configurational factor that depends upon the physical model and the assumptions underlying the derivation of the isotherm, $\theta$ is the surface coverage, $\mathrm{C}_{\mathrm{inh}}$ is the inhibitor's concentration in the bulk solution, $\alpha$ is the molecular interaction and $\mathrm{K}_{\mathrm{ads}}$ is the adsorption constant.

Table 7 shows the most commonly used isotherms for studying the adsorption mechanism of an inhibitor on a metal electrode surface [35-43]. The meaning of the parameters in the table is as follows:

Table 7. Used adsorption isotherms.

\begin{tabular}{|c|c|c|c|}
\hline Author & Isotherm & Eqn. & Ref. \\
\hline Langmuir & $k c=\frac{\theta}{1-\theta}$ & $(11)$ & [35] \\
\hline Frumkin & $k c=\frac{\theta}{1-\theta} \exp (-f \theta)$ & (12) & [36] \\
\hline Hill-de Boer & $k c=\frac{\theta}{1-\theta} \exp \left(\frac{\theta}{1-\theta}\right) \exp (-f \theta)$ & (13) & {$[37,38]$} \\
\hline Parsons & $k c=\frac{\theta}{1-\theta} \exp \left[\frac{2-\theta}{(1-\theta)^{2}}\right](-f \theta)$ & (14) & [39] \\
\hline Damaskin-Parsons & $k c=\frac{\theta}{(1-\theta) x} \exp (-f \theta)$ & $(15)$ & [40] \\
\hline Kastening-Holleck & $k c=\frac{\theta}{\chi(1-\theta)^{X}}\left(1-\theta+\frac{\theta}{\chi}\right)^{\mathrm{X}-1)} \exp (-f \theta)$ & $(16)$ & [41] \\
\hline Flory-Huggins & $k c=\frac{\theta}{X(1-\theta)^{x}}$ & $(17)$ & [41] \\
\hline Dhar-Flory-Huggins & $k c=\frac{\theta}{(1-\theta){ }^{x} \exp (X-1)}$ & (18) & {$[41]$} \\
\hline Bockris-Swinkels & $k c=\frac{\theta}{(1-\theta)^{x}} \times \frac{[\theta+\chi(1-\theta)]^{\left(x^{-1}\right)}}{x^{2}}$ & (19) & [42] \\
\hline El-Awady-Abd-El-Nabey-Aziz & $(k c)^{y}=\left(\frac{\theta}{1-\theta}\right)$ & (20) & [43] \\
\hline
\end{tabular}


It is noted that the inhibitor was adsorbed on the metallic surface, according to the Langmuir isotherm model (Fig. 7). The experimental data gave a good curve fitting for the applied adsorption isotherms as the correlation coefficients $\left(\mathrm{R}^{2}=\right.$ 0.999). As the adsorption isotherm in $1.0 \mathrm{M} \mathrm{HCl}$ is of the Langmuir-type, with a slope of almost unity, there is a monolayer of the inhibitor species without lateral interaction between the adsorbed species. So, the adsorption constant, $\mathrm{K}_{\mathrm{ads}}$, is related to the free energy of adsorption, $\Delta \mathrm{G}^{*}$ ads, by the following equation (14) [45]:

$$
K_{a d s}=\frac{1}{55.55} \exp \left(-\frac{\Delta G_{a d s}^{*}}{R T}\right)
$$

where 55.55 value represents the water concentration in a solution by $\mathrm{mol} \mathrm{L}^{-1}, \mathrm{R}$ is the universal gas constant and $\mathrm{T}$ is the absolute temperature.

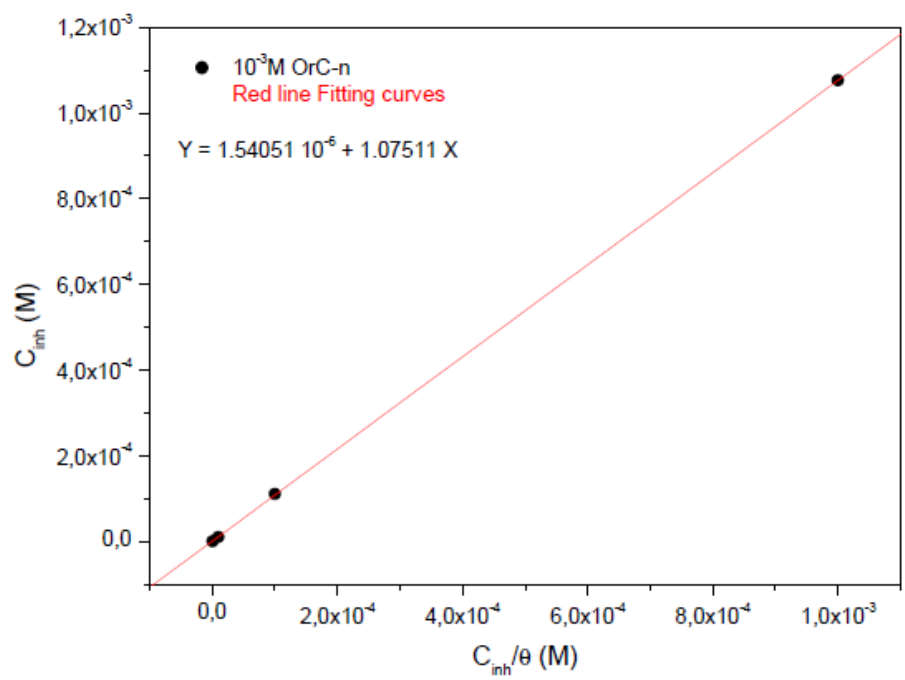

Figure 7. Plot of the Langmuir adsorption isotherm of P1 on the carbon steel surface at $298 \pm 2 \mathrm{~K}$.

The Langmuir isotherm model is, in many cases, too simple. It can be inferred that the process under study is spontaneous, and that the inhibitor is physically adsorbed onto the metal surface. This isotherm assumes that the adsorbed molecule only occupies one site and that there is no interaction with other adsorbed molecules. The relation between the adsorption constant $\left(\mathrm{K}_{\mathrm{ads}}\right)$ and adsorption free energy $\left(\Delta \mathrm{G}^{0}\right.$ ads $)$ is known as:

$$
K_{a d s}=e^{-\Delta G_{S} / R T}
$$

where $\mathrm{R}$ is the universal gas constant and $\mathrm{T}$ is the absolute temperature. The value for the Gibbs energy of adsorption, $\Delta \mathrm{G}^{0}$ ads, can be calculated, and for P1, $\Delta \mathrm{G}_{\text {ads }}^{0}=-37.6 \mathrm{~kJ} \mathrm{~mol}^{-1}$ is found.

\section{Corrosion kinetic parameters}

The data above presented in Table 6 revealed that P1 took its inhibition efficiency at all temperatures range. This behavior confirmed the higher adsorption equilibrium constant, $\mathrm{K}_{\mathrm{ads}}$, values, indicating physisorption and 
chemisorption of P1 at the carbon steel surface. This result has been explained by some authors as a likely specific interaction between the iron surface and the inhibitor. So, Ivanov [44] explained this increase in temperature by the change in the nature of the adsorption mode; the inhibitor is being physically adsorbed at lower temperatures, while this physisorption is favored by an increase in temperature. The same phenomenon was explained by other authors as an increase in the surface coverage by the inhibitor [45]. Thus, at a high surface, coverage values, and the diffusion through the surface layer containing the inhibitor and corrosion products became the rate-determining step of the metal dissolution process [46]. Therefore, the inhibition properties of P1 can be explained by the kinetic model. The dependence of the corrosion value, $\mathrm{i}_{\text {corr, }}$ on the temperature can be regarded as an Arrhenius-type process given by equation (13) [48]:

$$
\ln i_{c o r r}=\ln A-\frac{E_{a}}{R T}
$$

where $E_{a}$ is the apparent activation energy of the corrosion process, $R$ is the universal gas constant, $\mathrm{A}$ is the Arrhenius pre-exponential constant and $\mathrm{T}$ is the absolute temperature.

In order to assure that the achieved surface coverage was close to the maximal value, the concentration which gives the best inhibiting efficiency was chosen. The Arrhenius plots for carbon steel in $1.0 \mathrm{M} \mathrm{HCl}$, without and with $10^{-3} \mathrm{M}$ of P1 according to equation (13), were presented in Fig. 8.

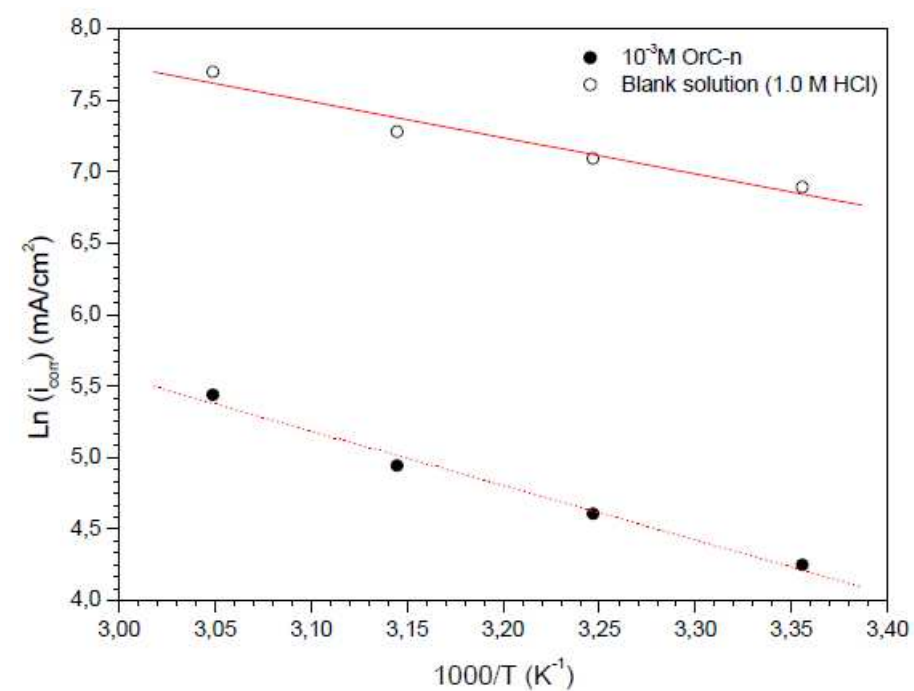

Figure 8. Arrhenius plots of carbon steel in $1.0 \mathrm{M} \mathrm{HCl},(\circ)$ without and $(\bullet)$ with $10^{-3} \mathrm{M}$ of P1.

These obtained plots are straight lines, and the slope of each straight line gives the activation energy value, $\mathrm{E}_{\mathrm{a}}$. It is noted that the increase on the corrosion rate is more pronounced with the rise of temperature for the free solution. So, in the presence of $\mathrm{P} 1$, the corrosion rate is slightly increased at explored temperatures. The $E_{a}$ values were found to be equal to $21.0 \mathrm{~kJ} \mathrm{~mol}^{-1}$ and $31.7 \mathrm{KJ} \mathrm{mol}^{-1}$, in the absence and presence of $10^{-3} \mathrm{M}$ of $\mathrm{P} 1$, respectively (Table 8 ). 
Table 8. Values of activation parameters, $\mathrm{E}_{\mathrm{a}}, \Delta \mathrm{H}_{\mathrm{a}}{ }^{*}$ and $\Delta \mathrm{S}_{\mathrm{a}}{ }^{*}$, for carbon steel in $1.0 \mathrm{M}$ $\mathrm{HCl}$ in the absence and presence of $10^{-3} \mathrm{M}$ of $\mathrm{P} 1$.

\begin{tabular}{|c|c|c|c|}
\hline Compounds & $E_{a}\left(k J J ~ m o l^{-1}\right)$ & $\Delta \mathbf{H}_{\mathrm{a}}{ }^{*}\left(\mathrm{~kJ} \mathrm{~mol}^{-1}\right)$ & $\Delta S_{a^{*}}{ }^{*}\left(J\right.$ mol$\left.^{-1} K^{-1}\right)$ \\
\hline Blank solution & 21.0 & 18.5 & -126.0 \\
\hline $10^{-3} \mathrm{M}$ of $\mathrm{P} 1$ & 31.7 & 29.0 & -112.5 \\
\hline
\end{tabular}

The decrease in the inhibitor's efficiency with an increasing temperature, which referred to a higher value of $E_{a}$, when compared to the free solution, was interpreted as an indication of the electrostatic character of the inhibitor's adsorption. So, the investigated inhibitor significantly energetically blocked some of the active sites on the metal surface, in an inhomogeneous way. In general, the inhibitor adsorbed at the most active sites of the surface with lowest $\mathrm{E}_{\mathrm{a}}$, thus isolating them. Other active sites of higher $\mathrm{E}_{\mathrm{a}}$ take part in the other stages of the corrosion process.

In addition, this change in $\mathrm{E}_{\mathrm{a}}$ with $\mathrm{P} 1$ addition can be attributed to the change in the corrosion process mechanism, in the presence of adsorbed inhibitor molecules [48].

Other kinetic data are accessible using the alternative formulation of the Arrhenius equation, which is (24) [50]:

$$
\ln \frac{i_{\text {corr }}}{T}=\left(\ln \left(\frac{R}{N h}\right)+\frac{\Delta S_{a}^{*}}{R}\right)-\frac{\Delta H_{a}^{*}}{R T}
$$

where $\mathrm{h}$ is Plank's constant, $\mathrm{N}$ is Avogadro's number, $\Delta \mathrm{S}_{\mathrm{a}} *$ is the entropy of activation and $\Delta \mathrm{H}_{\mathrm{a}}^{*}$ is the enthalpy of activation.

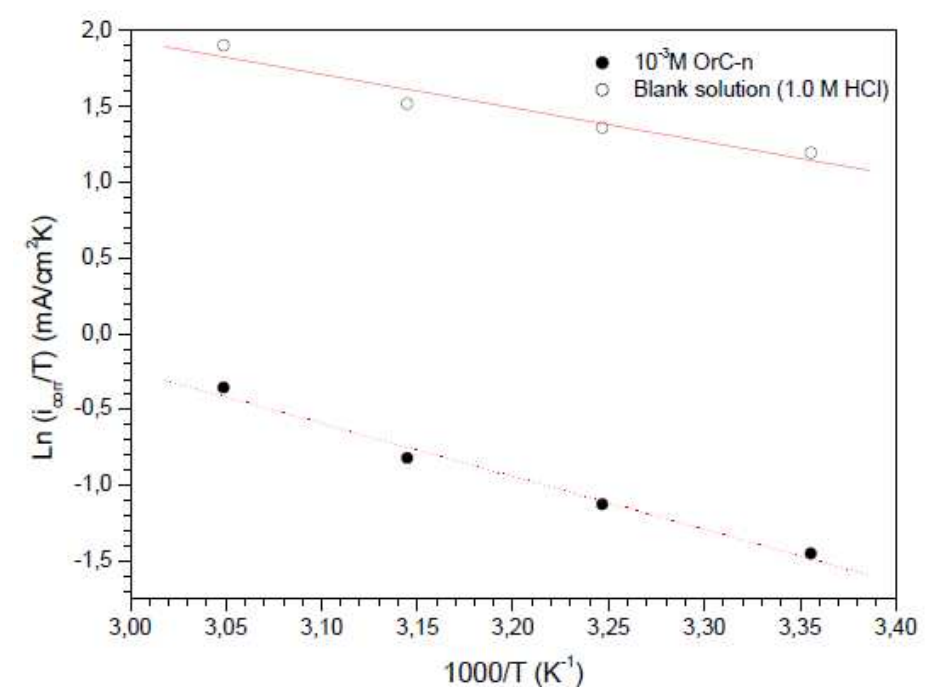

Figure 9. Transition-state plots for carbon steel in $1.0 \mathrm{M} \mathrm{HCl}$ (a) without and (b) with $10^{-3} \mathrm{M}$ of $\mathrm{P} 1$.

Plots of $\mathrm{Ln}\left(\mathrm{i}_{\mathrm{corr}} / \mathrm{T}\right)$ versus the reciprocal of temperature $(1 / \mathrm{T})$ of carbon steel in 1.0 $\mathrm{M} \mathrm{HCl}$, without and with $10^{-3} \mathrm{M}$ of P1, are presented in Fig. 9. Straight lines are obtained with a slope of $\left(-\Delta \mathrm{H}_{\mathrm{a}}{ }^{*} / \mathrm{R}\right)$ and an intercept of $\left(\ln \mathrm{R} / \mathrm{Nh}+\Delta \mathrm{S}_{\mathrm{a}}{ }^{*} / \mathrm{R}\right)$. The values of $\Delta \mathrm{H}_{\mathrm{a}}{ }^{*}$ and $\Delta \mathrm{S}_{\mathrm{a}}{ }^{*}$ were calculated and are listed in Table 8 . The positive sign of the enthalpies, $\Delta \mathrm{H}_{\mathrm{a}}{ }^{*}$, improved the endothermic nature of the 
carbon steel dissolution process, whereas large negative values of entropies, $\Delta \mathrm{S}_{\mathrm{a}}{ }^{*}$, implied that the activated complex in the rate determining step represents an association rather than a dissociation step, meaning that a decrease in disordering takes place on going from reactants to the activated complex [48-52].

\section{Conclusions}

Concluding the experimental part, it was clearly demonstrated that all used techniques are able to characterize and follow the corrosion inhibition process promoted by 2-(4,5-diphenyl-4,5-dihydro-1h-imidazol-2-yl)-5-methoxyphenol (P1). The following conclusions can be drawn:

1. The corrosion rate of carbon steel decreased with an increased inhibitor's concentration, reaching a minimum at $10^{-3} \mathrm{M}$.

2. 2-(4,5-diphenyl-4,5-dihydro-1h-imidazol-2-yl)-5-methoxyphenol exhibited good inhibition properties for carbon steel corrosion in a $1.0 \mathrm{M} \mathrm{HCl}$ solution, and increased with an increased concentration of inhibitor.

3. The obtained results showed that P1 acted as a mixed-type inhibitor of carbon steel corrosion in $1.0 \mathrm{M} \mathrm{HCl}$.

4. EIS measurement results indicated that the resistance of the carbon steel electrode increased with the inhibitor's concentrations, reaching a maximum at $10^{-3} \mathrm{M}$ of $\mathrm{P} 1$.

5. The inhibition efficiency of P1 can be stabilized by the participation of the two adsorption modes, physisorption and chemisorption.

6. Thermodynamic adsorption parameters $\left(\Delta \mathrm{H}_{\mathrm{a}}{ }^{*}, \Delta \mathrm{S}_{\mathrm{a}}{ }^{*}\right.$ and $\left.\Delta \mathrm{G}_{\mathrm{a}}{ }^{*}\right)$ showed that the studied inhibitor was adsorbed on the carbon steel surface by an endothermic and spontaneous process.

7. Reasonably good agreement was observed between the obtained data from weight loss, potentiodynamic polarization curves and electrochemical impedance spectroscopy techniques.

\section{References}

1. El Kacimi Y, Touir R, Galai M, et al. J Mater Environ Sci. 2016;7:371.

2. Hussin MH, Kassim MJ, Razali NN, et al. Arab J Chem. 2011;1878.

3. Abbouda Y, Abourriche A, Saffaj T, et al. Mater Chem Phys. 2007;105:1.

4. James AO, Oforka NC, Abiola K. Int J Electrochem Sci. 2007;2:284.

5. Ebenso EE, Niger. J. Chem Res. 2001;6:12.

6. Galai M, El Gouri M, Dagdag O, et al. J Mater Environ Sci. 2016;7:1562.

7. Elkacimi Y, Achnin M, Aouine Y, et al. Port Electrochim Acta. 2012;30:53.

8. El Kacimi Y, Azaroual MA, Touir R, et al. Euro-Mediterr J Environ Integr. 2017;2:1.

9. Naderi E, Jafari AH, Ehteshamzadeh M, et al. Mater Chem Phys. 2009; 115:852.

10. Bentiss F, Lagrenee M, Traisnel M, et al. Corros Sci. 1999;41:789.

11. O‘zcan M, Dehri I. Prog Org Coat. 2004;51:181.

12. Ehteshamzade M, Shahrabi T, Hosseini MG. Appl Surf Sci. 2006;252:2949. 
13. Alaoui K, El Kacimi Y, Galai M, et al. Anal Bioanal Electrochem. 2016;8:830.

14. Shukla SK, Quraishi MA. J Appl Polym Sci. 2012;124:5130.

15. Alaoui K, El Kacimi Y, Galai M, et al. J Mater Environ Sci. 2016;7:2389.

16. ASTM G-81. Annual Book of ASTM Standards. 1995.

17. Stern M, Geary AL. J Electrochem Soc. 1957;104:56.

18. AbdelAal MS, Radwan S, El Saied A. Br Corros J. 1983;18:2.

19. Hmamou DB, Salghi R, Zarrouk A, et al. Ind Eng Chem Res. 2013;52:14315.

20. Ateya BG, El-Khair MBA, Abdel-Hamed IA. Corros Sci. 1976;16:163.

21. Li W, He Q, Zhang S, et al. J Appl Electrochem. 2008;38:289.

22. Quraishi MA, Ahmad S, Venkatachari G. Bull Electrochem. 1996;12:109.

23. Riggs Jr OL. Corrosion inhibition. 2nd ed. Houston, TX; 1973.

24. Ghareba S, Omanovic S. Corros Sci. 2010;52:2104.

25. Gerengi H, Darowicki K, Bereket G, et al. Corros Sci. 2009;51:2573.

26. Brug GJ, van Den Eeden ALG, Sluyters-Rehbach M, et al. J Electroanal Chem. 1984;176:275.

27. Moradi M, Duan J, Du X. Corros Sci. 2013;69:338.

28. Tang Y, Zhang F, Huc S, et al. Corros Sci. 2013;74:271.

29. Schultze JW, Wippermann K. Electrochim Acta. 1987;32:823.

30. Galai M, Rbaa M, El Kacimi Y, et al. Anal Bioanal Electrochem. 2017;9:80.

31. Hsu CH, Mansfeld F. Corrosion. 2001;57:747.

32. Khamis E. Corrosion. 1990;46:6.

33. Sastri VS. Corrsion inhibitors. New York: John Wiley \& Sons; 1998.

34. Do D. Adsorption analysis: equilibria and kinetics. London: Imperial College Press; 1998.

35. Langmuir I. J Am Chem Soc. 1918;40:1361.

36. Frumkin AN. Z Phys Chem. 1925;116:466.

37. Hill TL. J Chem Phys. 1952;20:141.

38. de Boer JH. The dynamical character of adsorption. Oxford: Oxford University Press; 1953.

39. Parsons R. J Electroanal Chem. 1964;8:93.

40. Damaskin BB, Petrii OA, Batrakov VV. in: Adsorption of Organic Compounds on Electrodes. New York: Plenum Press; 1971.

41. Kastening B, Holleck L. Talanta. 1965;12:1259.

42. Bockris JOM, Swinkels DAJ. J Electrochem Soc. 1964;111:736.

43. El-Awady AA, Abd-El-Nabey BA, Aziz SG. J Electrochem Soc. 1992;139:2149.

44. Hongbo F. Beijing: Chemical Industry Press; 2002. p. 166.

45. Ali SA, Al-Muallem HA, Saeed MT, et al. Corros Sci. 2008;50:664.

46. Popova A. Corros Sci. 2007;49:2144.

47. Putilova I, Balezine S, V. Barannik V. In: Bishop E, editor. Metalic corrosion inhibitors. London, England; 1960.

48. Raicheff R, Valcheva K, Lazarova E. Proceedings of the Seventh European Symposium on Corrosion Inhibitors. Ferrara, Italy; 1990. p. 48. 
49. Herrag L, Hammouti B, Elkadiri S, et al. Corros Sci. 2010;52:3042.

50. Marsh J. Advanced organic chemistry. 3rd ed. New Delhi: Wiley Eastern; 1988.

51. Galai M, El Gouri M, Dagdag O, et al. J Chem Pharm Res. 2015;7:712.

52. Dahmani M, Et-Touhami A, Al-Deyab SS, et al. Int J Electrochem Sci. 2010;5:1060. 